\title{
Family Physician Geriatricians Do Mostly Geriatric Care: Is This a Problem for Our Specialty?
}

\author{
Kenneth Brummel-Smith, MD
}

In this issue, Peterson et $\mathrm{al}^{1}$ report that the majority of family physicians with Certificates of Added Qualifications (CAQs) in Geriatrics self-report practicing primarily geriatrics. Almost $40 \%$ of those surveyed reported spending $>80 \%$ of their time devoted to geriatric patients. Another 20\% reported spending $60 \%$ to $80 \%$ of their time with older patients. These figures raise many more questions than are answered by the data. Are these percentages different from the amount of time family physicians with other types of CAQs spend in their practices? Are family physician geriatricians a different "breed" than those who practice across a broader age spectrum? How is the "silver tsunami" affecting decisions of physicians with geriatric CAQs regarding the allocation of time within their practice? Could it be that many family physician geriatricians are simply getting older and seeing their practice age with them? Perhaps most controversial is whether this degree of "specialization" is inherently harmful to the discipline of family medicine.

My analysis of these questions is strongly influenced by my personal journey in family medicine and geriatrics. I am an "early adopter." I saw family practice (the term used in those days) as the natural counterpart to my 1960s-era nonconformity. I graduated high school in 1967, the same year Gayle Stephens was starting one of the first family practice residencies, and I read voraciously the writings

From the Department of Geriatrics, Florida State University College of Medicine, Tallahassee.

Funding: none.

Conflict of interest: none declared.

Corresponding author: Kenneth Brummel-Smith, MD, Department of Geriatrics, Florida State University College of Medicine, 1115 West Call St, Suite 4305, Tallahassee, FL 32306-4300 (E-mail: ken.brummel-smith@med.fsu.edu).

\section{See Related Article on Page 314.}

of Dr. Stephens and Ian McWhinney. I was (and am) passionate about the family as a unit of care and the psychosocial approach.

Later, in 1980, as a young residency faculty, my program director asked me to attend a Society of Teachers of Family Medicine meeting on integrating geriatrics into family medicine education. I jumped at the chance because it meant a free trip to Boston! Once there, however, I was bowled over by the presentations of David Kinney, Richard Ham, and other family physicians. The prospect of being able to help anyone to function better salved the wound that disease-based medical care inflicted on me. Over the next 3 years I transformed myself into a geriatrician, and by 1984 I too was practicing $>80 \%$ geriatrics.

When the American Board of Family Practice was considering joining the American Board of Internal Medicine in creating the first CAQ, a number of us met with the American Board of Family Practice to advocate in favor of the proposal. There was considerable opposition; however, we felt strongly that the care of older people should not be seen as the province of one specialty. In addition, we felt the fundamentals we learned in family practice training - continuity, the family as a unit of care, community-based thinking, and the psychosocial approach—would be important to this new, growing area of medicine.

Over time, new CAQs have been added. Family medicine now has 6: geriatric medicine, adolescent medicine, hospice and palliative medicine, pain medicine, sleep medicine, and sports medicine. But many family physicians with other CAQs do not spend the majority of time doing that "subspecialty." We have little information about how much time family physicians with other CAQs spend on that special area of interest, and more research into this question is needed. We do know that only about $6.7 \%$ of family physicians spend $>80 \%$ of their time doing emergency or urgent care, but there is no 
CAQ for that area. ${ }^{2}$ I was unable to find studies similar to that of Peterson et $\mathrm{al}^{1}$ regarding CAQs, but it seems unlikely that many family physicians with CAQs spend the majority of their time in any of these, except possibly hospice and palliative medicine.

Perhaps a major reason that so many family physician geriatricians spend so much of their time doing geriatrics is because of the demand. Older adults account for $26 \%$ of all physician office visits, $34 \%$ of all prescriptions, $35 \%$ of all hospital stays, and $90 \%$ of all nursing home residents. ${ }^{3}$ The deficit of geriatricians in the United States is well documented. There are currently about 7,500 certified geriatricians in the United States. The American Geriatric Society calculates need assuming that $30 \%$ of elders will need care by a geriatrician, and with a panel size of 700 older adults, then 17,000 geriatricians are needed now. That number is expected to rise to 30,000 in 2030 , when the silver tsunami is expected to peak. ${ }^{4}$ Certain areas of the county have severe shortages of geriatricians, and rural areas are the most affected. ${ }^{5}$ Importantly, good evidence shows that family physician geriatricians are more likely to practice in rural areas. In addition, in many cities as many as $12 \%$ of primary care physicians (family physicians and general internists) are not accepting new Medicare patients. ${ }^{6}$ Anecdotally, many physicians with a CAQ apparently do not want this to be known so as not to attract a larger number of Medicare patients. The simple fact is that finding a doctor who is not just willing but enjoys caring for older people is likely driving family physician geriatricians to focus on geriatrics.

The shortage of family physician geriatricians also affects training programs. Geriatrics is a required part of family medicine residency training, yet there were only 1099 geriatrician faculty in the entire United States in 2010. In addition, many faculty have heavy clinical loads, limiting their time for teaching. A interesting dynamic occurs in some residencies: other faculty "punt" to the geriatrician their difficult cases "for teaching purposes," thereby increasing the amount of time the geriatric faculty spend in geriatric care.

The existence of so few faculty also affects residents' decisions to pursue fellowship. Having an inspiring mentor strongly affects a resident's training choices and is one of the reasons so few family medicine residents pursue fellowship training in geriatrics. In 2014 there were 509 Accreditation Council for Graduate Medical Education-accredited slots for geriatric fellowships. Graduates of family medicine residencies are eligible for either internal medicine- or family medicine-based fellowships. A total of 455 of those slots were available because of lack of funding or faculty, and only 239 of those 455 slots $(53 \%)$ were filled. ${ }^{7}$

As of 2012 there were 44 accredited family medicine geriatric fellowship programs. That year, 66 of 109 positions were filled, most with graduates of family medicine programs. With almost 500 accredited family medicine residencies, staffing with family medicine geriatricians is a challenge. In addition, the geriatric workforce is itself aging and moving toward retirement. Just as the wave is hitting, the bulwarks are disappearing.

Another likely reason for so many family physician geriatricians "specializing" in geriatrics is because practice scope is being restricted in many other areas of family medicine. The number of family physicians providing pediatric, maternity, and surgical care continues to decline. The proportion of family physicians providing maternity care declined from $23.3 \%$ in 2000 to $9.7 \%$ in 2010 . Those continuing to provide that service spent only $10 \%$ of their time doing so. ${ }^{8}$ Even the provision of care for women's general health needs has decreased from $73 \%$ of family physicians providing the service in $2003 \%$ to $51 \%$ in $2009 .{ }^{9}$

Bazemore et $\mathrm{al}^{10}$ showed that $83 \%$ of family physicians provided internal medicine-related care, $73 \%$ provided pediatric care, and $65 \%$ provided geriatric care. However, the percentage of time spent with each group is not clear based on that study. That older patients see doctors 2 to 5 times as frequently as younger patients is well known. Many family physician geriatricians likely see their pediatric patients simply age into being "internal medicine" patients, and these then age into being geriatric patients.

Last, some family practice-based fellowship programs have developed to address the needs of rural elders. The program at Michigan State University has developed a distributed program with 9 family medicine residencies that enable rural physicians to get fellowship training at those sites. ${ }^{11}$ No other program in internal medicine is doing that. This type of program is critical because rural physicians are at great risk of limiting the access of older people to their practice. $^{12}$ 
The most difficult question to answer is whether "subspecialization" in geriatrics is harmful to the specialty of family medicine. I submit that it is not harmful. The bottom line is that more geriatricians are needed to serve the present and coming population of elders and to teach other physicians. The true value of a specialty is what social good it serves, and all medical specialties should be measured by how much good they provide to patients, not how they affect their parent specialty. In addition, family physician geriatricians are created within the value system of family medicine, and all the values that we hold dear-continuous, comprehensive, and compassionate care-are critical to high-quality geriatric care. If some family physicians are spending the vast majority of their time caring for elders, we are all the better for it.

\section{References}

1. Peterson LE, Cochrane A, Bazemore AW, Petterson S. Reported practice patterns among family physicians with a geriatrics certificate of added qualifications. J Am Board Fam Med 2015;28:314-5.

2. Petterson S, Peterson L, Phillips RL, et al. One in fifteen family physicians principally provide emergency or urgent care. J Am Board Fam Med 2014; 27:447-8.

3. Institutes of Medicine. Retooling for an aging America: building the health care workforce. Washington, DC: National Academies Press; 2008.

4. Geriatrics Workforce Policy Studies Center. The demand for geriatric care and the evident shortage of geriatrics healthcare providers. New York: American Geriatrics Society; 2013. Available from: http://www. americangeriatrics.org/files/documents/Adv_Resources/ demand_for_geriatric_care.pdf. Accessed February 27, 2015.

5. Geriatrics Workforce Policy Studies Center. 2008 Geriatrics physician workforce by county. New York: American Geriatrics Society; 2008. Available from: http://www.americangeriatrics.org/files/ documents/Adv_Resources/2008_Geriatrician_ Shortage_by_County.pdf. Accessed February 27, 2015.

6. Cubanski J, Neuman P. Medicare doesn't work as well for younger, disabled beneficiaries as it does for older enrollees. Health Aff (Millwood) 2010;29: 1725-33.

7. Carek PJ, Anthony E. Geriatric medicine: update from the Geriatric RC-FM. Presented at the American Geriatric Society 2013 Annual Meeting, Grapevine, TX. Available from: http://adgap.americangeriatrics.org/ toolkits/presentations/Peter_Carek2013.pdf. Accessed February 27, 2015.

8. Tong STC, Makaroff LA, Xierali IM, et al. Proportion of family physicians providing maternity care continues to decline. J Am Board Fam Med 2012;25: 270-1.

9. Xierali IM, Puffer JC, Tong STC, Bazemore AW, Green LA. The percentage of family physicians attending to women's gender-specific health needs is declining. J Am Board Fam Med 2012;25:406-7.

10. Bazemore AW, Petterson S, Johnson N, et al. What services do family physicians provide in a time of primary care transition? J Am Board Fam Med 2011; 24:635-6.

11. Foley K, Neuberger M, Noel M, Sleight D, vanSchagen J, Wadland W. Advancing geriatrics fellowship programs through a community-based residency network. Fam Med 2013;45:719-25.

12. Gunderson A, Menachemi N, Brummel-Smith K, Brooks R. Physicians who treat the elderly in Florida: trends indicating concerns. J Rural Health 2006; 22:224-8. 